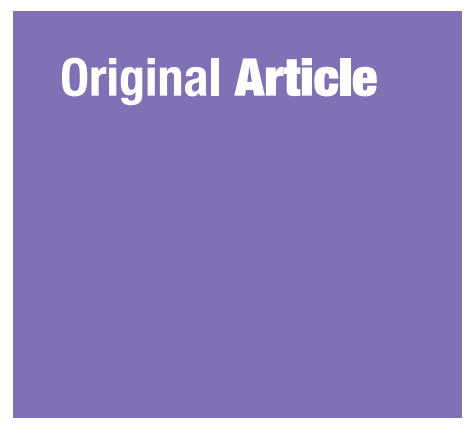

Submitted: 15 May 2019 Accepted: 8 Jan 2020

Online: 27 Feb 2020

\section{Effects of Carbohydrate Mouth Rinsing on Salivary Lysozyme, Mood States and Running Performance Among Recreational Runners}

\author{
Ayu Suzailiana Muhamad, Nurul Fatin Raihan Mohd Puad, \\ Garry KuAN
}

Exercise and Sports Science Programme, School of Health Sciences, Universiti Sains Malaysia, Kelantan, Malaysia

To cite this article: Muhamad AS, Mohd Puad NFR, Kuan G. Effects of carbohydrate mouth rinsing on salivary lysozyme, mood states and running performance among the recreational runners. Malays $J$ Med Sci. 2020;27(1):87-96. https://doi.org/10.21315/mjms2020.27.1.9

To link to this article: https://doi.org/10.21315/mjms2020.27.1.9

\begin{abstract}
Introduction: Carbohydrate (CHO) mouth rinsing can enhance sports performance through a central action mediated by receptors in the mouth. This study examined the effect of a CHO mouth rinse on salivary lysozyme concentrations, mood states and running performances.

Methods: Ten males recreational runners were randomised to three running trials with a 1 week recovery period between the trials. Each trial involved running at $75 \%$ maximum heart rate (HRmax) for $1 \mathrm{~h}$, followed by a $15 \mathrm{~min}$ time trial. The participants used a CHO mouth rinse, placebo (PLA) solution or control (CON, no solution) every 15 min during the exercise. Heart rate (HR), rating of perceived exertion (RPE) and mood states were recorded pre-, during and post-exercise. Saliva samples were collected pre-, post- and $1 \mathrm{~h}$ post-exercise.

Results: There was no significant interaction and time effect $(P>0.05)$ on the salivary lysozyme concentration and running performance, but it was significant $(P<0.05)$ for HR and RPE (increase in all trials). However, there was no significant difference $(P>0.05)$ in salivary lysozyme concentrations, running performances, HR values or RPE between the trials. Mood states were not significantly different $(P>0.05)$ between the trials, but one of the mood sub-scales showed a significant $(P<0.001)$ time effect (increase fatigue in all trials).

Conclusion: CHO mouth rinsing did not affect physiological parameters, salivary lysozyme concentrations, mood states or running performance among recreational runners.
\end{abstract}

Keywords: mouth rinsing, antimicrobial proteins, Brunel mood scale, exercise, recreational athletes

\section{Introduction}

Carbohydrate (CHO) intake during exercise can delay the onset of fatigue and improve performance during prolonged exercise (1). However, ingesting too much $\mathrm{CHO}$ can have detrimental effects. For example, highly concentrated $\mathrm{CHO}$ solutions and drinks with high osmolality have been linked to the development of gastrointestinal discomfort (2). As $\mathrm{CHO}$ is not swallowed during mouth rinsing, this might be a good strategy to improve sports performance without inducing gastrointestinal discomfort during exercise. The first study in this area by Carter et al. (3) reported that rinsing with a CHO mouthwash may have beneficial effects during high-intensity exercise. Several later studies reported that $\mathrm{CHO}$ mouth rinsing improved both cycling (4) and running (5) performances. In addition, $\mathrm{CHO}$ mouth rinsing increased the total distance covered during a selfselected 30 min run (6) and a 60 min self-paced run (7) in comparison to a placebo (PLA) mouth rinse. 
The mechanism by which $\mathrm{CHO}$ mouth rinsing increases sports performance remains unclear. However, according to previous research, the mechanism may involve a group of receptors in the oral cavity with connections to reward areas in the brain (8). Based on this idea, activation of these areas in the brain leads to a reduced perception of exertion during exercise (4) and possibly reduced feelings of discomfort (9). Some evidence suggests that the magnitude of performance improvements with $\mathrm{CHO}$ mouth rinsing may be dependent on several factors, including the duration of fasting (10) and time of mouth rinsing (11). Based on this premise, the physiological status of the body, such as a fasted or fed state (4), could alter the central response to detecting $\mathrm{CHO}$ in the mouth. There is also evidence that the duration of mouth rinsing is important, with rinsing for $10 \mathrm{sec}$ better than 5 sec in terms of exercise performance, suggesting a dose response to the duration of mouth rinsing (11).

Several studies reported that athletes who performed intensive and prolonged exercise had an elevated risk of minor illnesses, particularly upper respiratory tract infections (12, 13). However, to date, no published studies have reported the effects of $\mathrm{CHO}$ mouth rinsing on mucosal immunity and mood states in response to exercise. As mucosal immunity in association with innate non-specific defence acts as the first line of defence against pathogens, allergens and antigen presentation (14), it would be interesting to investigate whether $\mathrm{CHO}$ mouth rinsing might enhance mucosal immunity among athletes. In addition, as previous studies reported that the perception of exertion and feelings of discomfort declined with $\mathrm{CHO}$ mouth rinsing $(4,9)$, it would be interesting to determine whether $\mathrm{CHO}$ mouth rinsing improved athletes' mood states. Hence, the purpose of this study was to investigate the effects of $\mathrm{CHO}$ mouth rinsing on mucosal immunity, mood states and running performance among recreational runners.

\section{Methods}

\section{Research Design and Randomisation}

In this randomised, placebo-controlled, double-blinded and cross-over study, the participants were randomised to three running trials: CHO, PLA or control (CON). The recovery period between the trials was 1 week. The participants were randomised using computer generated randomised software (www. randomize.net). The CON trial did not involve mouth rinsing. In the CHO and PLA trials, the participants were given a plastic cup containing $25 \mathrm{~mL}$ of CHO or PLA, which they used as a mouth rinse every $15 \mathrm{~min}$ during the exercise. This study was conducted at the Sports Science Laboratory, Universiti Sains Malaysia (USM), Kelantan.

\section{Participants}

The sample size was calculated by using PS Power and Sample Size Calculation version 3.0.43. Based on a previous study (11), the power of study was set at $80 \%$ with $95 \%$ confident interval, the standard deviation (SD) observed was $1.2 \mathrm{~km}$ of cycling performance and the difference in population mean was set at $1.16 \mathrm{~km}$ of cycling performance. The calculated sample size was 10 participants.

Students $(N=10)$ attending USM were recruited using the convenience sampling method via a poster placed on notice boards in the campus. The selection criteria were: male sex, recreational athlete, healthy, aged 18-26 years old and a non-smoker. The health status of the participants was assessed during the recruitment process using the Physical Activity Readiness Questionnaire (PAR-Q) form (available online). Only those who answered 'No' to all the questions in the first section of the questionnaire were recruited. Throughout the study period, the participants abstained from taking any supplements known to affect immune function.

\section{Research Procedures}

The participants came to the laboratory at 8.30 a.m. after an overnight fast from 11.00 p.m. (plain water was permitted during this fasting period). Each participant's body weight was measured and the first saliva sample was collected by 5 min un-stimulated dribbling into a sterile bijou tube. Each participant was asked to sit on a chair, lean their head forward and let the saliva passively dribble into the tube, without using any tongue or mouth movement.

Subsequently, the participants were asked to complete the Brunel mood scale (BRUMS) to provide an assessment of mood states (15). The BRUMS is a validated 24-item questionnaire. It contains six sub-scales, with each of the subscales containing four mood descriptors. The sub-scales are anger, confusion, depression, fatigue, tension and vigour. The BRUMS was 
validated and translated into the Malay language by Hashim et al. (16) in a study on 355 young Malaysian athletes, with alpha coefficients ranging from $0.72,0.64,0.73,0.69,0.65$ and 0.58 for tension, depression, anger, vigour, fatigue and confusion, respectively.

After completing the BRUMS, the participants performed the running trial $(\mathrm{CHO}$, PLA or CON). Each trial started with a warmup by running on a motorised treadmill at $50 \%$ of maximum heart rate (HRmax) for $5 \mathrm{~min}$, followed by running for another $60 \mathrm{~min}$ at $75 \%$ HRmax. The CON trial did not involve mouth rinsing. For CHO and PLA trials, at every 15 min, participants used CHO or PLA solution, respectively, as a mouth rinse for $10 \mathrm{sec}$ before expectorating back into the cup. Immediately following the 60 min run, the participants were asked to run as fast as they could in 15 min (time trial) whereby they can adjust their running speed as desired. The running distance covered during this 15 min time trial was recorded.

The resting HR and rating of perceived exertion (RPE) were recorded before and after the warm-up, during the trial and after the time trial. Second and third saliva samples were collected upon finishing the time trial and $1 \mathrm{~h}$ post-exercise. Post-exercise, all the participants completed the BRUMS again.

\section{Preparation of CHO and Placebo Solutions}

The CHO solution was prepared by adding $64 \mathrm{~g}$ of glucose into $1000 \mathrm{~mL}$ of water (4). The PLA solution was prepared by adding $17 \mathrm{~g}$ of commercially available non-caloric sweetener stevia into $1000 \mathrm{~mL}$ of water. Its colour and taste were similar to the $\mathrm{CHO}$ solution but contained no carbohydrate. Both solutions were prepared and labelled by a laboratory staff to ensure double blinding.

\section{Saliva Samples Analysis}

Saliva samples were centrifuged at 12,000 rpm for 10 min by using a centrifuge. Its liquid part was transferred into a labelled tube and kept in the freezer at $-20{ }^{\circ} \mathrm{C}$ until further analysis of salivary lysozyme was carried out by using a commercially available reagent kit via the ELISA method.

\section{Statistical Analysis}

By using Statistical Package for Social Science version 23.0, the normality of all the data was examined through the Kolmogorov-Smirnov test. One-way analysis of variance (ANOVA) was used to analyse differences of participants' age, body weight, height and BMI between trials. Two-way ANOVA with repeated measures was performed to determine the significance of the differences of HR, RPE, lysozyme concentration and BRUMS scores between trials and within each trial. The difference was considered statistically significant at $P<0.05$. All values were presented as mean (standard deviations).

\section{Results}

\section{Physiological Characteristics of the Participants}

Mean age, weight, height and body mass index (BMI) of all the 10 participants are shown in Table 1. The values were analysed using descriptive statistics. One-way ANOVA analysis revealed that mean age, body weight, height and BMI were not significantly different $(P>0.05)$ between groups.

\section{Heart Rate (HR)}

There was a significant interaction effect $\left(F_{(12,46)}=0.578, P=0.018\right)$ and main effect of time $\left(F_{(6,22)}=289, P<0.001\right)$ on HR values in the trials, with HR values significantly increasing in all trials from baseline to the end of the exercise. However, there was no significant difference in HR values among the trials $\left(F_{(2,27)}=0.475, P=\right.$ $0.627)$. The average $\mathrm{HR}$ values at baseline and at the end of each trial are shown in Table 1.

\section{Rate of Perceived Exertion}

There was a significant time $\times$ trial interaction effect $\left(F_{(12,46)}=0.514, P=0.048\right)$ and main effect of time $\left(F_{(6,22)}=52, P<0.001\right)$ on RPE in the trials, with RPE increasing significantly in all trials from baseline to the end of the exercise. However, there was no significant difference in RPE among the trials $\left(F_{(2,27)}=0.257\right.$, $P=0.775)$. Table 1 shows the average RPE values at baseline and at the end of each trial.

\section{Running Performance}

There was no significant difference $\left(F_{(2,18)}=\right.$ 2.591, $P=0.103)$ in the running distance covered during the time trial in the three trials (Figure 1). The mean running distance covered in the $\mathrm{CHO}$, PLA and CON (no mouth rinse) trials was 2.34, 2.33 and $2.23 \mathrm{~km}$, respectively. 
Table 1. Physical and physiological characteristics of the participants

\begin{tabular}{lcccc}
\multirow{2}{*}{\multicolumn{1}{c}{ Parameters }} & \multicolumn{3}{c}{ Mean (SD) } & \multirow{2}{*}{ P-value } \\
\cline { 2 - 4 } Age (years old) & CHO & PLA & CON & 0.442 \\
Body weight (kg) & $21.2(4.4)$ & $22.2(2.8)$ & $22.0(3.7)$ & 0.094 \\
Height (cm) & $60.7(11.8)$ & $62.8(8.5)$ & $61.7(5.6)$ & 0.167 \\
Body mass index (kg/m²) & $165.8(4.6)$ & $166.8(8.6)$ & $164.8(8.1)$ & 0.318 \\
HR-baseline (beats/min) & $22.1(1.5)$ & $22.6(2.6)$ & $22.7(2.4)$ & Time effect: $P=0.001$ \\
HR-post-trial (beats/min) & $162.7(3.4)$ & $78.5(4.4)$ & $76.1(4.6)$ & Group effect: $P=0.627$ \\
RPE-baseline (scale 6-20) & $6.0(0.0)$ & $6.0(0.0)$ & $6.0(0.0)$ & Time effect: $P=0.001$ \\
RPE-post-trial (scale 6-20) & $15.2(1.2)$ & $15.8(2.7)$ & $14.5(5.1)$ & Group effect: $P=0.775$ \\
\hline
\end{tabular}

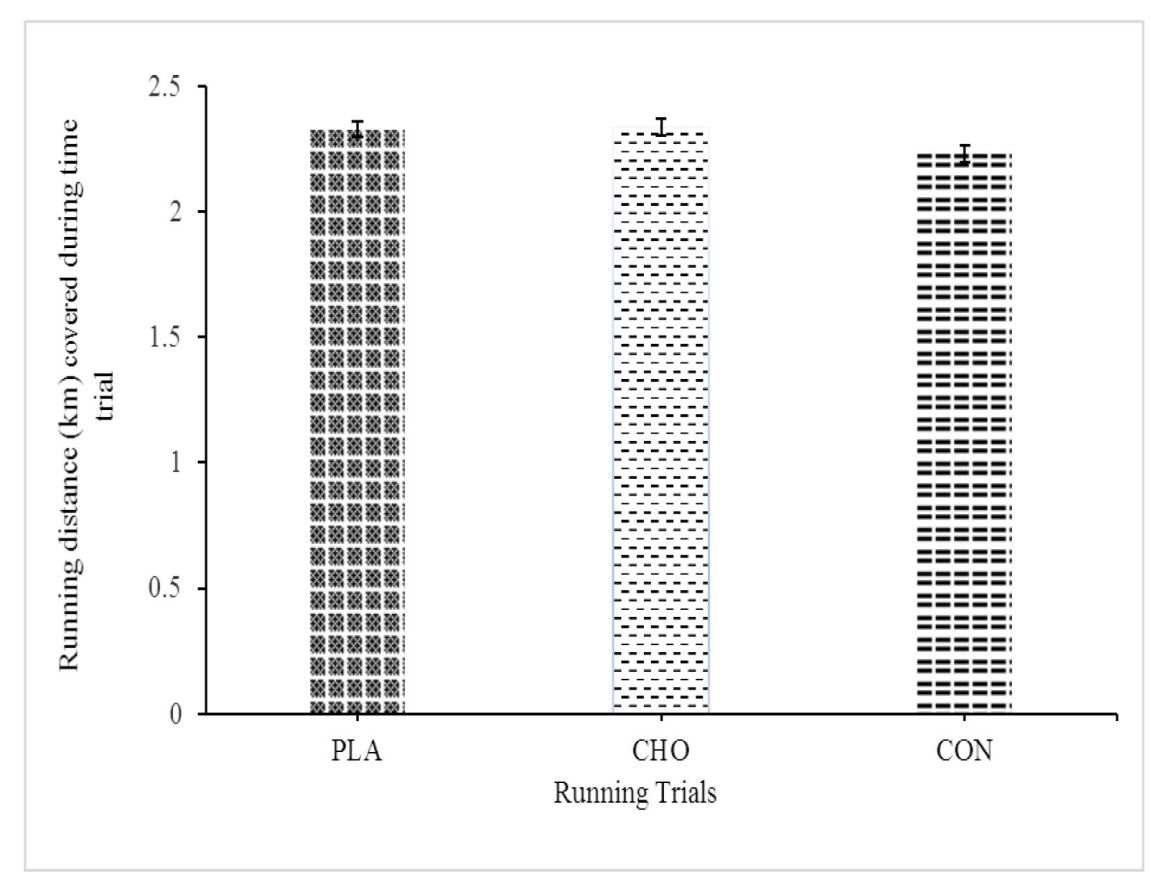

Figure 1. Running distance covered $(\mathrm{km})$ during the 15 min time trial

\section{Salivary Lysozyme Concentration}

There was no significant time $\times$ trial interaction effect $\left(F_{(4,54)}=0.101 ; P=0.101\right)$ on salivary lysozyme concentration (Figure 2). There was also no significant main effect of time $\left(F_{(2,54)}=1.813, P=0.173\right)$ on salivary lysozyme concentration during the trials and no significant difference $\left(F_{(2,27)}=0.141, P=0.869\right)$ on lysozyme concentration among the trials.

\section{BRUMS}

There was a significant time effect for fatigue $\left(F_{(1,27)}=18.43, P<0.001\right)$ (Table 2) but not on other sub-scales. However, there was no significant interaction between time and trial on all sub-scales. In addition, there was also no significant difference on all sub-scales between trials. 
Original Article | CHO mouth rinsing on lysozyme, mood and running

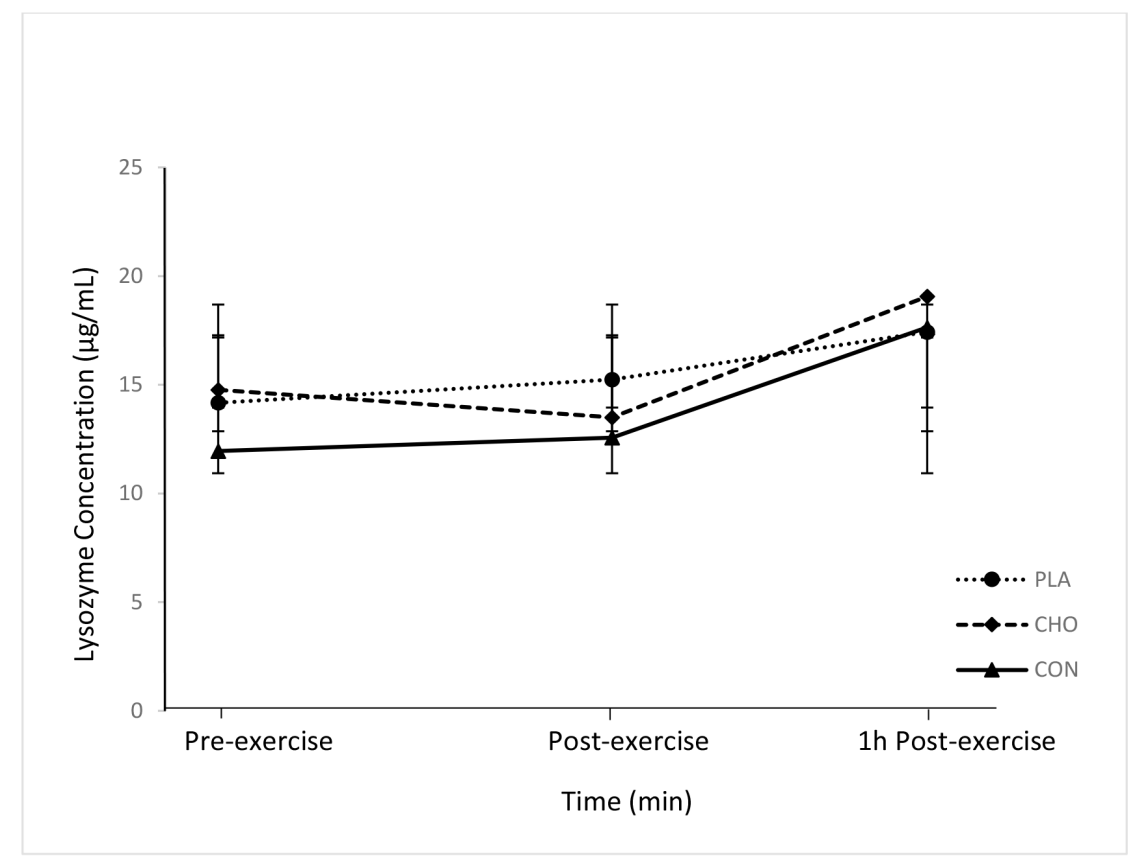

Figure 2. Lysozyme concentration $(\mu \mathrm{g} / \mathrm{mL})$ in all trials

Table 2. BRUMS scores in all trials

\begin{tabular}{|c|c|c|c|c|c|c|}
\hline \multirow{2}{*}{ Variables } & \multirow{2}{*}{ Groups } & \multirow{2}{*}{$\begin{array}{c}\text { Pre-trial } \\
\text { Mean (SD) }\end{array}$} & \multirow{2}{*}{$\begin{array}{l}\text { Post-trial } \\
\text { Mean (SD) }\end{array}$} & \multirow{2}{*}{$\begin{array}{c}\text { Time Effect } \\
F \text {-stat (df) } \\
P \text {-value }\end{array}$} & \multirow{2}{*}{$\begin{array}{c}\text { Time* }^{*} \\
\text { Group } \\
\text { F-stat (df) } \\
\text { P-value }\end{array}$} & \multirow{2}{*}{$\begin{array}{c}\text { Group } \\
\text { Effect } \\
\boldsymbol{F} \text {-stat (df) } \\
\text { P-value }\end{array}$} \\
\hline & & & & & & \\
\hline \multirow[t]{3}{*}{ Vigour } & PLA & $60.6(11.3)$ & $53.4(7.6)$ & $1.51(1,27)$ & $0.91(2,27)$ & $0.01(1,27)$ \\
\hline & $\mathrm{CHO}$ & $57.2(13.1)$ & $57.2(7.1)$ & \multirow{2}{*}{$P=0.293$} & \multirow{2}{*}{$P=0.416$} & \multirow{2}{*}{$P=0.996$} \\
\hline & $\mathrm{CON}$ & $57.6(11.3)$ & $57.0(10.2)$ & & & \\
\hline \multirow[t]{3}{*}{ Anger } & PLA & $44.8(1.6)$ & $45.8(4.4)$ & $1.17(1,27)$ & $0.28(2,27)$ & $0.81(1,27)$ \\
\hline & $\mathrm{CHO}$ & $44.4(1.2)$ & $44.7(2.2)$ & \multirow{2}{*}{$P=0.287$} & \multirow{2}{*}{$P=0.757$} & \multirow{2}{*}{$P=0.455$} \\
\hline & $\mathrm{CON}$ & $45.1(2.4)$ & $47.4(8.5)$ & & & \\
\hline \multirow[t]{3}{*}{ Confusion } & PLA & $47.2(4.2)$ & 48.6 (10.9) & $1.30(1,27)$ & $0.07(2,27)$ & $0.26(1,27)$ \\
\hline & $\mathrm{CHO}$ & $44.8(4.3)$ & $48.0(9.1)$ & \multirow{2}{*}{$P=0.264$} & \multirow{2}{*}{$P=0.936$} & \multirow{2}{*}{$P=0.775$} \\
\hline & $\mathrm{CON}$ & $44 \cdot 7(3 \cdot 3)$ & $47.7(13.0)$ & & & \\
\hline \multirow[t]{3}{*}{ Fatigue } & PLA & $48.4(7.8)$ & 56.9 (9.9) & $18.43(1,27)$ & $0.25(2,27)$ & $0.03(1,27)$ \\
\hline & $\mathrm{CHO}$ & $48.8(6.2)$ & $55.7(9.2)$ & \multirow{2}{*}{$P<0.001^{* * *}$} & \multirow{2}{*}{$P=0.784$} & \multirow{2}{*}{$P=0.974$} \\
\hline & $\mathrm{CON}$ & $50.2(9.6)$ & $55.9(10.6)$ & & & \\
\hline \multirow[t]{3}{*}{ Tension } & PLA & $54.8(14)$ & $51.4(13.8)$ & $0.03(1,27)$ & $0.24(2,27)$ & $1.50(1,27)$ \\
\hline & $\mathrm{CHO}$ & $49.1(9.5)$ & $49.4(10.6)$ & \multirow{2}{*}{$P=0.861$} & \multirow{2}{*}{$P=0.789$} & \multirow{2}{*}{$P=0.243$} \\
\hline & $\mathrm{CON}$ & $46.8(6.3)$ & $48.3(9.9)$ & & & \\
\hline \multirow[t]{3}{*}{ Depression } & PLA & $44.5(2.5)$ & $51.3(14.8)$ & $4.20(1,27)$ & $0.56(2,27)$ & $0.42(1,27)$ \\
\hline & $\mathrm{CHO}$ & $44.5(2.5)$ & $47.5(6.9)$ & \multirow{2}{*}{$P=0.050$} & \multirow{2}{*}{$P=0.581$} & \multirow{2}{*}{$P=0.659$} \\
\hline & $\mathrm{CON}$ & 44.8 (8.9) & $50.1(11.9)$ & & & \\
\hline
\end{tabular}

Notes: *** $(P<0.001)$ - Significantly different between pre- and post-trial 


\section{Discussion}

\section{Heart Rate}

In agreement with our findings, several other studies reported that $\mathrm{HR}$ increased progressively during exercise $(4,17)$. The increase in HR during exercise is due to the increased demand for oxygen supply to working muscles. Chronotropic and inotropic effects on the heart are stimulated by the noradrenergic sympathetic nervous system. In the present study, HR values were unaffected by mouth rinsing or the type of mouth rinsing solution used during prolonged exercise. Other studies reported similar observations (3, 17-19). The results suggest that a $\mathrm{CHO}$ mouth rinse during exercise does not affect HR and that the effect depends on the type, intensity and volume of the exercise (20).

\section{Rate of Perceived Exertion}

Perceived exertion is defined as physical sensations experienced by an individual during physical activity (21). In the present study, RPE rose from 6 to 17 in the Borg's scale in all the trials, showing that physical exertion perceived by the participants steadily increased over time, particularly at the end of the time trial in all the trials. Although perceived exertion is a subjective measurement, a person's exertion rating may provide a fairly good estimate of the actual heart rate values during physical activity (21). The present study did not detect any statistically significant difference in RPE between the trials. Similarly, previous studies that reported a performance benefit from $\mathrm{CHO}$ mouth rinsing reported no difference in subjects' perceived exertion $(3,4,10,22-24)$. In contrast, some studies $(9,19)$ reported lower RPE in a $\mathrm{CHO}$ mouth rinsing trial as compared with that in a PLA trial. The discordant findings might be attributed to different types of exercises and different exercise durations and intensities in the various studies.

\section{Running Performance}

In this study, running performance was determined by the running distance covered by the participants during each time trial. The results of the statistical analysis revealed no significant difference in the time trial running distance covered in the three trials (Figure 1). This finding was similar to that of a previous study on the effect of a $\mathrm{CHO}$ mouth rinse or
PLA on running performance (24). The authors detected no significant difference in the overall distance covered in a $45 \mathrm{~min}$ time trial in the $\mathrm{CHO}$ trial (6\% CHO) and PLA trial. In contrast, another study reported that recreational runners who used a CHO mouth rinse covered a greater running distance than those who used a PLA mouth rinse (17). Similarly, researchers found positive effects of $\mathrm{CHO}$ mouth rinsing on cycling performance $(3,22)$, reporting that cyclists who used a $\mathrm{CHO}$ mouth rinse completed a time trial significantly faster than those who used a PLA mouth rinse. All the previous studies (3, 4, 22, 23,25 ) that reported positive findings of a $\mathrm{CHO}$ mouth rinse on exercise performance involved higher intensity ( $\geq 75 \%$ of $\mathrm{VO}_{2} \max$ ) exercise than that performed in the present study, in which the participants performed lower exercise intensity. It is possible that the exercise protocol in the present study did not induce sufficient exertion to gain possible benefits from $\mathrm{CHO}$ mouth rinsing.

\section{Salivary Lysozyme Concentration}

In the present study, $\mathrm{CHO}$ mouth rinsing had no effect on salivary lysozyme concentrations (Figure 2). To date, there are limited reports on the effects of $\mathrm{CHO}$ mouth rinsing on salivary lysozyme concentrations. However, the salivary lysozyme concentration increased immediately after food consumption during the first hour of recovery after prolonged exercise in the $\mathrm{CHO}$ trial relative to that in the PLA trial (26). The increase in the lysozyme concentration during $\mathrm{CHO}$ feeding is associated with the secretion of saliva flow rate. The findings illustrate the importance of the saliva flow rate in the regulation of oral mucosal immunity (27-29).

In addition, this study found that the salivary lysozyme concentration was not significantly affected by the prolonged exercise in all the trials. A previous study on elite rowers (30) also observed no significant change in salivary lysozyme concentrations in response to exercise. This finding was inconsistent with that of some previous studies (31-34), which found an increase in salivary lysozyme secretion following exercise. In these studies, lysozyme responses increased significantly with moderate exercise intensity and increased further with high-intensity exercise (35). These findings suggest that the lysozyme secretion rate depends on the exercise intensity, where exercise intensity is directly proportional to the lysozyme secretion rate. 
In general, exercise-induced alterations in mucosal secretions were largely dependent on the exercise intensity or duration. Higher intensity (> 70\% $\mathrm{VO}_{2} \max$ ) or longer duration (> $40 \mathrm{~min}$ ) exercise appeared to elicit greater concentrations and secretion rates of antimicrobial polypeptides $(34,36,37)$. For example, Allgrove et al. (34) reported significant increases in salivary lysozyme concentrations after exercise at $75 \% \mathrm{VO}_{2} \max$ on a cycle ergometer. Similarly, Usui et al. (37) noted temporary increases in salivary lysozyme concentrations in 10 young male volunteers after prolonged strenuous exercise at $75 \% \mathrm{VO}_{2} \max$ for 60 min. Davison et al. (36) reported significant increases in salivary lysozyme concentrations after $2.5 \mathrm{~h}$ of cycling exercise at $60 \%$ of $\mathrm{VO}_{2}$ max. In contrast, low-intensity or short-duration exercise did not appear to significantly change antimicrobial polypeptide responses compared to resting values (34). In a cycle ergometer exercise at $50 \% \mathrm{VO}_{2} \mathrm{max}$, non-significant changes in salivary lysozyme concentration were reported after exercise for approximately 22 min (34). Furthermore, West et al. (30) reported that exercise had no effect on salivary lysozyme concentrations.

According to previous research, increased secretion of lysozymes from salivary glands during exercise is a function of the accumulation of proteins over time (38). Some authors proposed that increased sympathetic nervous system activity may explain the acute increase in salivary lysozymes after high-intensity exercise (30). Others suggested that an increase in the concentration of salivary lysozymes after exercise might confer improved immunity to infection $(29,30)$. Chronic stress was shown to be associated with reduced secretion of salivary lysozymes (39). Hence, it could be suggested that prolonged intense exercise may have a negative effect on the concentration of lysozymes in the upper respiratory tract. Although prolonged intense exercise causes transient perturbations in mucosal immunity, the relative load or intensity of exercise required to produce such perturbations varies among individuals, depending on physical capacity, training history and fitness levels. These factors need to be considered when determining the intensity and duration to be applied in experimental settings (30). Thus, this inconsistency might confound the results of the study.

\section{BRUMS}

To date, there is limited research on perceptual responses and mood during exercise. In the present study, we investigated mood responses following CHO, PLA and CON trials. $\mathrm{CHO}$ mouth rinsing did not affect mood states as assessed by the BRUMS. However, the exercise itself significantly increased feelings of fatigue but not on the other sub-scales (Table 2). Mood states fluctuate as a situation changes, and there is no ideal mood for superior performance (40). The researcher has indicated that there was a two-way relationship between mood and emotion. In the study, mood shaped athletes' emotions, and subjective experience resulted in a particular mood state. Lane et al. (41) showed that depressed mood acted as a moderator of other manifestations of mood in athletic performance. In the presence of depression, increased levels of negative mood states, such as anger, tension, confusion and fatigue, had adverse effects on performance. Ali et al. (18) reported that mouth rinsing or ingestion did not influence the profile of mood scale (POMS) score. However, they observed an interaction effect for the 'vigour' sub-scale, with higher ratings over time in CHO mouth rinsing compared to a PLA mouth rinse and $\mathrm{CHO}$ ingestion trials. Rollo et al. (5) reported that mouth rinsing with a $\mathrm{CHO}$ solution significantly increased Feeling Scale ratings, with the $\mathrm{CHO}$ group having higher scores for pleasurable feelings immediately prior to a 30-min run than a PLA mouth rinse solution group. In a magnetic resonance imaging study, Chambers et al. (4) reported that $\mathrm{CHO}$ mouth rinsing enhanced motivation and activity of motor control centres. They suggested that CHO mouth rinsing could enhance mood by stimulating pleasure and reward centres in the brain. The activation of these brain regions may influence emotions and behaviour and consequently exercise performance (42). Despite positive findings of the effect of $\mathrm{CHO}$ mouth rinsing on mood in previous studies, $\mathrm{CHO}$ mouth rinsing did not significantly enhance mood states during prolonged exercise in the present study. We speculate that reduced stress induced by the exercise protocol employed in this study and the fitness level of the participants may have hindered the potential benefits of $\mathrm{CHO}$ mouth rinsing. 


\section{Conclusion}

It can be summarised that $\mathrm{CHO}$ mouth rinsing has no significant effects on the running distance covered during the time trial, HR, RPE, lysozyme concentration and mood states. However, it was noted that prolonged exercise significantly increased HR, RPE and fatigue subscale of mood. As a conclusion, the present study found that $\mathrm{CHO}$ mouth rinsing has no beneficial effects on physiological parameters, salivary lysozyme responses, running performance and mood states during prolonged exercise among recreational runners.

\section{Acknowledgements}

We would like to thank all the participants and Sports Science Laboratory staff of Health Campus Universiti Sains Malaysia for their commitment and cooperation in this study.

\section{Ethics of Study}

The study was approved by the Human Research Ethics Committee of USM (USM/ $\mathrm{JEPeM} / 16020070$ ) and was conducted in accordance with the Declaration of Helsinki.

\section{Conflict of Interest}

None.

\section{Funds}

This work was supported by the Research University Individual (RUI) grant [1001/ PPSP/812184] from Universiti Sains Malaysia.

\section{Authors' Contributions}

Conception and design: ASM, GK

Analysis and interpretation of the data: ASM,

GK, NFRMP

Drafting of the article: ASM

Critical revision of the article for important intellectual content: ASM, GK

Final approval of the article: ASM, GK

Provision of study materials or patients: ASM

Statistical expertise: ASM, GK

Administrative, technical, or logistic support: ASM, GK

Collection and assembly of data: NFRMP

\section{Correspondence}

Dr Ayu Suzailiana Muhamad

MSc (Universiti Sains Malaysia), PhD

(Loughborough, United Kingdom)

Lecturer

Exercise and Sports Science Programme,

School of Health Sciences, Universiti Sains

Malaysia,

16150 Kubang Kerian,

Kelantan, Malaysia.

Tel: +609 7676973

Fax: +6097677515

E-mail: ayu_suzailiana@usm.my

\section{References}

1. Jeukendrup AE. A step towards personalized sports nutrition: carbohydrate intake during exercise. Sports Med. 2014;44(Suppl 1):S25S33. https://doi.org/10.1007/s402 79-014-0148-z

2. de Oliveira EP, Burini RC. Carbohydratedependent, exercise-induced gastrointestinal distress. Nutrients. 2014;6(10):4191-4199. https://doi.org/10.3390/nu6104191

3. Carter JM, Jeukendrup AE, Jones DA. The effect of carbohydrate mouth rinse on 1-h cycle time trial performance. Med Sci Sports Exerc. 2004;36(12):2107-2111.

4. Chambers ES, Bridge MW, Jones DA. Carbohydrate sensing in the human mouth: effects on exercise performance and brain activity. J Physiol. 2009;587(8):1779-1794.

5. Rollo I, Homewood G, Williams C, Carter J, Goosey-Tolfrey VL. The influence of carbohydrate mouth rinse on self-selected intermittent running performance. Int $J$ Sport Nutr Exerc Metab. 2015;25(6):550-558.

6. Burke LM, Hawley JA, Wong SH, Jeukendrup AE. Carbohydrates for training and competition. J Sports Sci. 2011;29(Suppl 1):S17-S27. https:// doi.org/10.1080/02640414.2011.585473

7. Dougherty KA, Baker LB, Chow M, Kenney WL. Two percent dehydration impairs and six percent carbohydrate drink improves boys' basketball skills. Med Sci Sports Exerc. 2006;38(9):16501658. https://doi.org/10.1249/01.mss.0000227 $640.60736 .8 \mathrm{e}$ 
8. Gant N, Stinear CM, Byblow WD. Carbohydrate in the mouth immediately facilitates motor output. Brain Res. 2010;1350:151-158. https://doi. org/10.10 16/j.brainres.2010.04.004

9. Backhouse SH, Bishop NC, Biddle SJH, Williams C. Effect of carbohydrate and prolonged exercise on affect and perceived exertion. Med Sci Sports Exerc. 2005;37(10):1768-1773.

10. Beelen M, Berghuis J, Bonaparte B, Ballak SB, Jeukendrup AE, Van Loon LJC. Carbohydrate mouth rinsing in the fed state: lack of enhancement of time-trial performance. Int $J$ Sport Nutr Exerc Metab. 2009;19(4):400-409.

11. Sinclair J, Bottoms L, Flynn C, Bradley E, Alexander G, McCullagh S, et al. The effect of different durations of carbohydrate mouth rinse on cycling performance. Eur $J$ Sport Sci. 2014;14(3):259-264. https://doi.org/10.1080/17 461391.2013.785599

12. Krüger K, Mooren FC, Pilat C. The immunomodulatory effects of physical activity. Curr Pharm Des. 2016;22(24):3730-3748.

13. Simpson RJ, Kunz H, Agha N, Graff R. Exercise and the regulation of immune functions. Prog $\mathrm{Mol}$ Biol Transl Sci. 2015;135:355-380. https://doi. org/10.1016/bs.pmbts.2015.08.001

14. Gleeson M, Pyne DB. Special feature for the Olympics: Effects of exercise on the immune system: exercise effects on mucosal immunity. Immunol Cell Biol. 2000;78(5):536-544. https://doi.org/10.1111/j.1440-1711.2000.to1-8-.x

15. Terry PC, Lane AM, Lane HJ, Keohane L. Development and validation of a mood measure for adolescents. $J$ Sports Sci. 1999;17(11):861872.

16. Hashim HA, Zulkifli EZ, Hanafi, HAY. Factorial validation of Malaysian adapted Brunel mood scale in an adolescent sample. Asian $J$ Sports Med. 2010;1(4):185-194. https://doi. org/10.5812/asjsm.34838

17. Wright B, Davison G. Carbohydrate mouth rinse improves $1.5 \mathrm{~h}$ run performance: Is there a doseeffect? Int J Exerc Sci. 2013;6(4):328-340.
18. Ali A, Moss C, Ji MYY, Wilkinson A, Breier BH. Effect of mouth rinsing and ingestion of carbohydrate solutions on mood and perceptual responses during exercise. J Int Soc Sports Nutr. 2017;14(4):1-10. https://doi.org/10.1186/s129 70-016-0161-8

19. Fares EJ, Kayser B. Carbohydrate mouth rinse effects on exercise capacity in preand postprandial states. $J$ Nutr Metab. 2011;2011:385962. https://doi.org/10.1155/2011/ 385962

20. Sarmiento S, García-Manso JM, Martín-González JM, Vaamonde D, Calderón J, da Silva-Grigoletto ME. Heart rate variability during high-intensity exercise. J Syst Sci Complex. 2013;26:104-116. https://doi.org/10.1007/s11424-013-2287-y

21. Borg G. Borg's perceived exertion and pain scales. Champaign, IL: Human Kinetics; 1998.

22. Pottier A, Bouckaert J, Gilis W, Roels T, Derave W. Mouth rinse but not ingestion of a carbohydrate solution improves $1 \mathrm{~h}$ cycle time trial performance. Scand J Med Sci Sports. 2010;20(1):105-111. https://doi.org/10.1111/ j.1600-0838.2008.00868.x

23. Rollo I, Williams C. Effect of mouth-rinsing carbohydrate solutions on endurance performance. Sports Med. 2011;41(6):449-461. https://doi.org/10.2165/11588730-000000000ooooo

24. Whitham M, McKinney J. Effect of a carbohydrate mouthwash on running time-trial performance. $J$ Sports Sci. 2007;25(12):1385-1392.

25. Gam S, Guelfi KJ, Fournier PA. Opposition of carbohydrate in a mouth-rinse solution to the detrimental effect of mouth rinsing during cycling time trials. Int $J$ Sport Nutr Exerc Metab. 2013;23(1):48-56.

26. Da Costa RJ, Fortes MB, Richardson K, Bilzon JLJ, Walsh NP. The effects of post-exercise feeding on saliva antimicrobial proteins. Int $J$ Sport Nutr Exerc Metab. 2012;22(3):184-191.

27. Blannin AK, Robson PJ, Walsh NP, Clark AM, Glennon L, Gleeson M. The effect of exercising to exhaustion at different intensities on saliva immunoglobulin A, protein and electrolyte secretion. Int J Sports Med. 1998;19(8):547-552. https://doi.org/10.1055/s-2007-971958 
28. Oliver S, Laing S, Wilson S, Bilzon J, Walters R, Walsh N. Salivary immunoglobulin A response at rest and after exercise following a $48 \mathrm{~h}$ period of fluid and/or energy restriction. $\mathrm{Br} J$ Nutr. 2007;97(6):1109-1116. https://doi.org/10.1017/ Soo07114507 682919

29. Walsh NP, Blannin AK, Clark AM, Cook L, Robson PJ, Gleeson M. The effects of high-intensity intermittent exercise on saliva IgA, total protein and alpha-amylase. $J$ Sports Sci. 1999;17(2):129134. https://doi.org/10.1080/026404199366226

30. West NP, Pyne DB, Kyd JM, Renshaw GM, Fricker PA, Cripps AW. The effect of exercise on innate mucosal immunity. $\mathrm{Br} J$ Sports Med. 2010;44(4):227-231. https://doi.org/10.1136/ bjsm.2008.046532

31. Cole AM, Dewan P, Ganz T. Innate antimicrobial activity of nasal secretions. Infect Immun. 1999;67(7):3267-3275.

32. Ganz T. Antimicrobial polypeptides. J Leukoc Biol. 2004;75(1):34-38. https://doi.org/10.1189/ jlb.0403150

33. Gillum T, Kuennen M, McKenna Z, Castillo M, Jordan-Patterson A, Bohnert C. Exercise does not increase salivary lymphocytes, monocytes, or granulocytes, but does increase salivary lysozyme. J Sports Sci. 2017;35(13):1294-1249. https:// doi.org/10.1080/02640414.2016.1221522

34. Allgrove JE, Gomes E, Hough J, Gleeson M. Effects of exercise intensity on salivary antimicrobial proteins and markers of stress in active men. $J$ Sports Sci. 2008;26(6):653-661. https://doi.org/10.1080/0264041070171679o

35. Ligtenberg AJM, Brand HS, Van Den Keijbus PAM, Veerman EC. The effect of physical exercise on salivary secretion of $\mathrm{MUC}_{5} \mathrm{~B}$, amylase and lysozyme. Arch Oral Biol. 2015;60(11):16391644. https://doi.org/10.1016/j.archoralbio.2015. 07.012
36. Davison G, Allgrove J, Gleeson M. Salivary antimicrobial peptides (LL-37 and alphadefensins HNP1-3), antimicrobial and IgA responses to prolonged exercise. Eur $J$ Appl Physiol. 2009;106(2):277-284. https://doi. org/10.1007/s00421-009-1020-y

37. Usui T, Yoshikawa T, Orita K, Ueda SY, Katsura $\mathrm{Y}$, Fujimoto S, et al. Changes in salivary antimicrobial peptides, immunoglobulin A and cortisol after prolonged strenuous exercise. Eur J App Physiol. 2011;111(9):2005-2014. https:// doi.org/10.1007/s00421-011-1830-6

38. Dubin RF, Robinson SK, Widdicombe JH. Secretion of lactoferrin and lysozyme by cultures of human airway epithelium. Am J Physiol Lung Cell Mol Physiol. 2004;286(4):L750-L755. https://doi.org/ 10.1152/ajplung.00326.2003

39. Koh D, Yong Y, Ng V, Chia SE. Stress, mucosal immunity, upper respiratory tract infections, and sickness absence. $J$ Occup Environ Med. 2002;44(11):987-988.

40. Kleinert J. Mood states and perceived physical states as short term predictors of sport injuries: Two prospective studies. Int $J$ Sport Psychol. 2007;5(4):340-351. doi.org/10.1080/1612197X. 2007.9671840

41. Lane AM, Terry PC, Beedie CJ, Curry DA, Clark N. Mood and performance: Test of a conceptual model with a focus on depressed mood. Psychol Sport Exerc. 2001;2(3):157-172. https://doi. org/10.1016/S1469-0292 (01)00007-3

42. Kringelbach ML, Rolls ET. The functional neuroanatomy of the human orbitofrontal cortex: evidence from neuroimaging and neuropsychology. Prog Neurobiol. 2004;72(5):341-372. https://doi.org/10. 1016/j. pneurobio.2004.03.006 